\title{
Rosalía Meníndez Martínez \\ (2013), Las escuelas primarias de la ciudad de México en la modernidad porfiriana, Universidad Pedagógica Nacional, México
}

\author{
Amalia Nivón \\ Universidad Pedagógica Nacional, \\ Unidad Ajusco, México, D.F. \\ amalianivon@yahoo.com.mx
}

En este libro se estudia la vida escolar de las escuelas primarias de la ciudad de México durante el porfiriato, su estrecha relación con la modernización del régimen y los cambios expresados en las prácticas escolares, en las que participaron niños, maestros, autoridades y padres de familia. En esos espacios escolares estuvieron en contacto con libros diseñados específicamente para la enseñanza de contenidos, los cuales debían ser trabajados conforme a tiempos, horarios, programas y actividades dentro y fuera de las aulas escolares.

Más que una mirada historiográfica, la autora se acerca al tema desde la historia cultural, es decir, la vida escolar y sus actores. Identifica a los funcionarios interesados en sistematizar, regular, reglamentar, organizar y planificar una educación que fortaleciera la figura de un Estado moderno, capaz de ser no sólo centralista y controlador respecto de la educación pública nacional, sino también de influir en las prácticas dentro de la vida escolar cotidiana y sus entornos socioculturales.

La gran cantidad de fuentes primarias consultadas por Rosalía Meníndez le permitieron abordar los cambios que experimentó el sistema educativo a través de las escuelas y sus actores. El punto de partida es la élite liberal de la década de los ochenta del siglo XIX, cuyas acciones propiciaron la aparición de nuevas ideas que evidenciaron la lucha entre el progreso y la tradición, para plantear en su lugar otras formas de entender las relaciones entre los individuos de una sociedad civilizada, y de éstos con la naturaleza.

El contexto se caracteriza por la transición de nuestro país hacia la modernidad, a partir de la fuerza política que toma la figura del Ejecutivo, justificado por el discurso positivista impulsado por lo que la autora denomina la élite porfirista. El gran proyecto modernizador 
de este periodo tuvo sus bases en la proyección de un ciudadano formado según los principios de un orden social sustentado en las instituciones educadoras, vinculadas directamente a los pobladores de las ciudades, donde era más probable que las autoridades federales ejercieran la gobernabilidad.

Este trabajo está integrado por ocho capítulos; en el primero se analiza el proyecto modernizador porfirista y la ciudad de México como modelo para todo el país en el plano político, económico y social, específicamente en los esfuerzos para reordenarla y embellecerla, hacerla segura, transitable y con servicios públicos a la altura de otras ciudades industriales de Europa. Como consecuencia de estas acciones, los municipios no lograron mayor desarrollo, de tal manera que un gran número de escuelas primarias mantuvo las prácticas difundidas por el sistema lancasteriano de enseñanza mutua, o la enseñanza privada del ámbito familiar o la Iglesia. El proceso de cambio educativo dio lugar a reglamentos y leyes que transformaron la manera de enseñar, de moverse en el espacio escolar, de vivir dentro y fuera del aula, de convivir en la ciudad y en sus alrededores.

El segundo capítulo describe el lugar de los infantes en los estudios históricos, desde la Antigüedad y la formación pedagógica del maestro urbano del siglo XIX. Hace referencia a la expansión de las escuelas primarias elementales, superiores y de adultos, así como la administración del ayuntamiento de la ciudad, según su financiamiento, tipos de escuela, condiciones y formas de organización. El manejo del tiempo escolar se examina en el tercer capítulo y se da continuidad al estudio de la importancia del niño en los espacios del adulto; en dichos espacios se le puede educar con valores y normas institucionales para vivir en disciplina, con atención a sus deberes y obligaciones. En esta parte, la autora se apoya en obras de Michel Foucault y Agustín Escolano para describir y analizar el uso del cuerpo y el tiempo en los espacios curriculares marcados por la institución escolar. La administración educativa se convierte en parte de la formación del profesor; y los directivos de escuela en aplicadores de normas reguladoras del ritmo de trabajo del profesor y de los aprendizajes a evaluar en los niños.

En el cuarto capítulo se estudia el plan curricular de la escuela primaria elemental, cuya mayor virtud se encontrará en la pretensión de poner orden a lo que se consideraba un caos, mediante la unificación de los programas y contenidos de enseñanza en el país. El principio del orden se tradujo en control curricular para optimizar el trabajo del profesor y los aprendizajes escolares, seguidos de principios racionales, objetivos, laicos y, sobre todo, acorde con los preceptos liberales de un Estado moderno. Este apartado describe los contenidos de enseñanza organizados para los niños y niñas, incluyendo asignaturas mínimas u obligatorias, por ejemplo, la enseñanza del español como lengua nacional — superpuesta a las demás lenguas de la región-, la enseñanza simultánea de la lectura y escritura, el tipo de letra, nociones de geografía, historia antigua y colonial, aritmética y sistema métrico de- 
cimal, instrucción cívica, geometría, nociones de ciencias físicas y naturales, a partir de lecciones de cosas. También incluyó asignaturas complementarias, como el inglés, dibujo, música, canto, manualidades, gimnasia para niñas y ejercicios militares para varones.

La autora puntualiza, sucintamente, los principios organizativos de un programa de curso, objetivos e incluso estrategias de aprendizaje, ideas que fueron debatidas por la élite intelectual de la época porfirista en tres congresos pedagógicos (1882, 1889 y 1890), en los que se expusieron temáticas semejantes a las planteadas en otros congresos educativos durante esta época en distintos países de Europa, América Latina y Estados Unidos. En los dos últimos congresos, funcionarios y autoridades educativas del gobierno federal discutieron y acordaron normas curriculares y pedagógicas basadas en criterios de uniformidad para las escuelas primarias, en términos de organización escolar por grupos de edad y grados, contenidos y formas de enseñanza generales y obligatorios, así como los perfiles profesionales y laborales de los maestros. Las rutinas escolares dieron paso a otras formas de tratar los temas de enseñanza y entender los conocimientos curriculares, mejor ligados al ámbito laboral de la industria, el comercio, la vida ciudadana, la salud pública y la higiene personal.

La autora dedica los capítulos quinto y sexto a los cambios en los métodos de enseñanza que debían realizar los maestros en las escuelas, para dejar atrás el método lancasteriano o de enseñanza mutua, difundido en el mundo por influencia del mercado capitalista y aplicado en México en 1822, durante la primera época de vida independiente. Las nuevas ideas pedagógicas llegaron también de Europa, por las experiencias escolares del suizo Johann Heinrich Pestalozzi y del alemán Friedrich Fröebel, con el denominado método objetivo e intuitivo, el juego escolar dentro y fuera del aula, como visitas guiadas, excursiones y fiestas cívicas, que debían ser parte de la formación básica de los maestros de primaria y preescolar. Los relatos cortos, publicados en periódicos y revistas por autores mexicanos, muestran la intención de recrear la vida cotidiana de los infantes, incluyendo actividades lúdicas. En estos relatos, los adultos introducían ideas moralizantes, con imágenes de ángeles o dibujos propios de las disciplinas curriculares, que podían releerse a los niños en la escuela o en casa. Los juegos al aire libre aportaron otra perspectiva a la enseñanza áulica, ya que la educación física daba fortaleza al cuerpo y propiciaba la higiene, por un lado, y acercaba al niño a la naturaleza mediante el desarrollo de sus habilidades de percepción para el conocimiento objetivo e intuitivo, por el otro.

La higiene escolar es un aspecto que Rosalía Meníndez estudia en el séptimo capítulo. Ella considera que es una expresión de la modernidad, presente en la escuela como un espacio público, donde se regula el comportamiento social en masa para lograr un cuerpo social sano, bello y disciplinado. Las escuelas de la ciudad de México se presentaron como el modelo urbano que debían imitar las escuelas en la mayor parte del país. La atención médica, a través de medidas de salud pública en las escuelas, dotó de mayores beneficios a 
sus pobladores, aun a los que no podían concluir la educación elemental, gracias a los programas de saneamiento en la ciudad, como la aplicación de vacunas y la instalación de drenaje, la construcción de hospitales, cementerios, mercados, el rastro, así como la limpia de calles, glorietas y alamedas.

El impacto positivo de estas medidas de salud pública fue favorecido por el pensamiento positivista, extensivo a la formación y organización académica de egresados de distintas profesiones liberales, que también se estudia en este capítulo. Se refiere, asimismo, a la manera en que los cambios en la higiene del cuerpo desde la escuela fueron discutidos en el congreso higiénico pedagógico de 1882, en el que se acordaron lineamientos normativos que debían difundirse y adoptarse en las escuelas, como la postura para leer, escribir, escuchar y hablar en clase, caminar, cantar o salir al recreo. El control sanitario conllevó a políticas públicas sobre los materiales de construcción, ubicación y mantenimiento de los servicios de los locales escolares, como baños para niños, niñas y adultos, aulas, cocina y patio; los libros y los materiales didácticos de uso diario; esto tuvo como objetivo que el supervisor y el médico escolar contribuyeran al control y prevención de las enfermedades infectocontagiosas frecuentes en los escolares.

El libro cierra con un apartado sobre cómo la política de gobierno del general Porfirio Díaz intentó contabilizar los principales cambios que tuvieron efecto durante los más de treinta años de su mandato. Las estadísticas plasman algunos cambios que las ciudades experimentaron en aumento poblacional y estilo de vida, comercio, transportes, comunicaciones, escuelas y otros servicios públicos administrados por los órganos de gobierno; parecía que dar cuenta de los recursos permitía hacer buen uso de las finanzas públicas. Sin embargo, las estadísticas mostraron realidades difícilmente posibles de uniformar por la vía de la modernidad y la paz porfirista.

Considero relevante destacar el marco teórico con el que la autora analiza la riqueza descriptiva de la vida social interna y externa de la escuela, es decir, la manera en que se acerca a la cultura escolar y a los actores políticos que intervinieron en los cambios propuestos por el proyecto educativo porfirista. Esta perspectiva histórica surge a finales del siglo XX y ha contribuido al estudio de las instituciones escolares. Inicialmente desarrollada por el historiador francés Dominique Julia, se ocupa del análisis de las normas que definen saberes a enseñar y conductas que deben inculcarse a través de las prácticas escolares que transmiten contenidos disciplinarios y cómo los agentes educativos involucrados incorporan comportamientos que responden a procesos de socialización. Rosalía Meníndez retoma al historiador francés André Chervel para destacar que el conocimiento escolar es resultado de una producción cultural específica, diferente de otros tipos de conocimiento social, y se caracteriza por proveer a los estudiantes de una determinada representación del mundo que habitan, 
en la cual se favorece la formación de identidades colectivas que desembocan en el desarrollo de lo que conocemos como conciencia nacional.

Para Rosalía Meníndez, el término cultura escolar denota prácticas y normas que definen a una escuela y sus actores. Se conforma tanto de aspectos formales, como de rasgos propios de quienes transitan por aquélla: lo que ahí ocurre da lugar a una experiencia que sería narrada en un tiempo y un espacio determinados, de ahí que no exista una sola cultura escolar, sino varias, pues cada escuela y sus actores experimentan una realidad diferente. El mundo escolar, conformado por prácticas y normas, permite que historiadores, educadores o especialistas en las disciplinas que ahí se enseñan se introduzcan en las instituciones para advertir un complejo campo de interacciones sociales, en el que confluyen, además de estudiantes, profesores, directivos y padres de familia, formas de organización escolar, políticas e ideologías de grupos ligados al aparato de gobierno y otros poderes del entorno escolar.

Este trabajo de Rosalía Meníndez Martínez es una invitación al estudio histórico de esas normas y prácticas escolares que envuelven muchas experiencias grabadas en la memoria de nuestros cuerpos a través del mobiliario, horarios y celebraciones; de nuestras formas de estudiar y aprender, rechazar, valorar y respetar como la colectividad que habita un lugar. 